\title{
A Study on Aluminium Levels in Patients Undergoing Haemodialysis at a Tertiary Care Hospital
}

\author{
Hafeez Abdul Kader ${ }^{2,3}$, Neelathahalli Kasturirangan Meera ${ }^{3}$, Abubakar Siddique ${ }^{1,3, \star}$, Ashfaque \\ Ahmed $^{2,3}$ \\ ${ }^{1}$ Department of Pharmacy Practice, Unaizah College of Pharmacy, Qassim University, SAUDI ARABIA. \\ ${ }^{2}$ United Doctors Hospitals, Jeddah, SAUDI ARABIA. \\ ${ }^{3}$ Department of Pharmacy Practice, Visveswarapura Institute of Pharmaceutical Sciences, Bengaluru-560070, Karnataka, INDIA..
}

\begin{abstract}
Introduction: Aluminium studied as a potentially toxic metal and is commonly found in earth's crust. Aluminium toxicity may lead to: aluminium-induced bone disease, microcytic anaemia and neurological manifestation, such conditions more particular seen in patients with chronic renal failure and principally patients on haemodialysis. Objectives: The objective of our study was to measure a serum aluminium levels in patients undergoing haemodialysis at tertiary care hospital, Bengaluru. Materials and Methods: This was a prospective study, conducted on 50 patients who were on maintenance haemodialysis for more than 6 months. $5 \mathrm{ml}$ of the blood was drawn from the antecubital vein from the patient before haemodialysis process. Collected blood samples were estimated for aluminium levels by GFAAS. The dialysis fluid and RO water were also tested similarly for presence of aluminium to correlate the possible contamination. Results: The results were; $6(12 \%)$ patients had serum aluminium levels within baseline i.e. $<20 \mu \mathrm{g} / \mathrm{L}, 18(36 \%)$ patients had serum aluminium levels between $21-60 \mu \mathrm{g} / \mathrm{L}$ and 26 (52\%) of the patients had serum aluminium levels above $60 \mu \mathrm{g} / \mathrm{L}$. The aluminium content varied in the dialysate fluid reaching greater than the standard safety limit. Conclusion: In our study we found that aluminium toxicity is a serious problem in patients undergoing haemodialysis. Patients performing haemodialysis for longer period showed higher level of aluminium. Patients age of 50 years and on haemodialysis for duration 3 years need to be monitored carefully for aluminium toxicity. The major source of elevated serum aluminium in our study participants appears to be dialysate fluid, use of aluminium utensils, OTC products and food habits of consult patients.
\end{abstract}

Key words: Aluminium toxicity, Haemodialysis, CRF, Nephrology, GFAAS.

\section{INTRODUCTION}

Aluminium is a trivalent, very reactive, the third most frequent element in the earth's crust and the most ample metal (8\%). Aluminium is considered as a potentially toxic metal and aluminium poisoning may lead to three types of disorders: aluminiuminduced bone disease, microcytic anemia and encephalopathy. Usually found in patients with chronic renal failure. ${ }^{1-6}$

Under normal physiological conditions, the usual daily intake of aluminium is $5-10$ $\mathrm{mg}$. This amount is filtered efficiently from the blood by the glomerulus of the kidney and eliminated completely. Individuals in renal failure loose this ability and become candidates for aluminium toxicity especially when they undergo dialysis treatment. ${ }^{7}$
Aluminium (Al) is the most ample metal on earth and human beings are often exposed to it. ${ }^{8}$ Dietary aluminium is omnipresent but in such minor quantities that it is not a essential source of concern in individuals with normal elimination capacity. Commonly water supplies may contain a higher concentration because usually water is treated with the element before supply to general populations. ${ }^{9} \mathrm{Al}$ toxicity is induce by disruption of homeostasis of metals such as magnesium, calcium and iron (Fe): in fact, $\mathrm{Al}$ mimics these metals in their biological functions and triggers many biochemical revision. ${ }^{10}$ In specific, $\mathrm{Al}$ both exerts direct genotoxicity in primary human neural cells ${ }^{11}$ and induces neurodegeneration, through an increase in Fe accumulation and oxygen
DOI: 10.5530/ijopp.13.3.41

Address for correspondence: Abubakar Siddique 'Department of Pharmacy Practice, Unaizah College of Pharmacy, Qassim University, Saudi Arabia.

${ }^{3}$ Department of Pharmacy Practice, Visveswarapura Institute of Pharmaceutical Sciences, Bengaluru-560070, Karnataka, India.

Phone no: +966534405236

Email Id: getabu2u@gmail.com

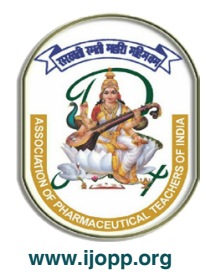


reactive species (ROS) production. ${ }^{12,13}$

Aluminium is well absorbed from the GI tract from the orally, parenterally through immunizations, through dialysate in patients on dialysis or as Total Parental Nutrition (TPN) infection, by means of the urinary mucosa through bladder irrigation and transversally from antiperspirants. Lactate, citrate and acerbate all facilitate GI tract retention. In case a genuine stack surpasses the body's excretory capacity, the abundance is kept in different tissues of the body, counting bone, brain, liver, heart, spleen and muscle. This excess accumulation causes morbidity and mortality through various mechanisms. Aluminium toxicity is usually occurring in patients with impaired renal function. Acute intoxication is very rare occur; however, in subjects in those aluminium clearance is impaired, it can be an important source of pathology. The elimination half-life of aluminium from the human brain is 7 years; this can result in total damage.

In patient with normal renal function Serum aluminium is ordinarily lower than 6 microgram $/ \mathrm{L} .{ }^{14}$ patter levels of serum aluminium ought be $<20$ microgram/l. on the off chance that levels of serum aluminium are between 20-60 micrograms/L, a rummage around for and elimination of all sources of aluminium ought to be performed. ${ }^{15}$

\section{Some of the sources of aluminium are Food}

Aluminium naturally occurring in tea coffee and some fresh fruits and vegetables. Also in processed food stuffs, food prepared from aluminium vessels, beverage packaging etc

Source of drinking water also contains aluminium in it as aluminium sulphate or alum is used as flocculating agent in municipal water supply. ${ }^{16}$

\section{Drugs}

Numerous drugs are often used in patients with renal insufficiency. Approximately 80 to 90 percent are given several other medicines for individuals with chronic kidney disease, e.g. antihypertensive, erythropoietin, iron supplements, medications for treating electrolyte imbalance, diuretics and heart failure medicines etc. Although drugs comply with quality related drug prescription pharmaceutics, aluminium can be an extra source of aluminium for patients as an impurity. In addition, not only active ingredients but additives, excipients and vehicles for the dilution or aggregation of the preparation are in the most common formulation. Many products can contain aluminium unintentionally in their formulation. Aluminium oxide can be one of its components and can therefore have a high amount of Aluminium. Talcum is a common excipient. Aluminium is present in raw materials for the production of medicines that are usually taken in chronic renal patients as an impurity.The products are also not specifically designed to produce medicines for chronic renal failure patients; no specific consideration is taken for the presence of aluminium. ${ }^{17}$

\section{Vaccination}

Metal aluminium was first added to vaccines in 1926. The purpose of the aluminium compounds is to dramatically boost the immune reaction to the vaccine and make it prolonged, since some of the aluminium remains in the site of injection for years. Aluminium has long been developed in medical applications such as vaccines adjuvant and a pathological hyperhidrosis with a low profile side-effect. ${ }^{18}$ In addition; giving the vaccines all at once exposes the brain to higher levels of neurotoxin aluminium as proven by the radiolabel aluminium. ${ }^{19}$

No recognized biological function in the human body is fulfilled by aluminium. Additionally, aluminium in many parenteral nutrition components, particularly calcium and phosphate additives, is a common contaminant. The human body has inherent protection mechanisms under normal circumstances that inhibit significant absorption of the ingested aluminium. An intact gastrointestinal tract usually allows aluminium to be absorbed by less than 1 per cent. Ninetynine percent of the aluminium is excreted from the body via renal function. ${ }^{20}$ Aluminium is used in consumer goods including: antacids, astringents, buffered aspirin, food additives, antiperspirants, cosmetics, medication packaging, etc.

Soil dust from mining and agricultural activities and also occupational exposure like welding, in paper industries, textile industries, in paints and others are the other possible sources of aluminium.

In dialysate fluid also there is some chance of contamination with aluminium. ${ }^{21}$ According to European Best Practice Guidelines for haemodialysis maximum aluminium concentration in dialysis fluid should not exceed from $10 \mu \mathrm{gl} / 1 .^{22}$

Aluminium causes two major types of toxic damage in cells. Aluminium, as a pro-oxidant, induces oxidative damage both by itself and in combination with iron. Also, aluminium competes with and replaces essential metals mainly $\mathrm{Mg}_{2+}$, iron and $\mathrm{Ca}_{2+}$ ions in or on proteins and their co-factors. ${ }^{23}$

Dialysis encephalopathy is a syndrome commonly found in dialysis patients with chronic renal insufficiency, 
characterized by dementia, expression alterations, myoclonias, asterixis and seizures, consistent with standard electroencephalogram alterations. These clinical findings show a poor prognosis, leading to mortality in most cases. ${ }^{22,24}$

Renal osteodystrophy, which is most evident in patients on renal replacement therapy, usually begins when the kidney function starts to deteriorate. Osteomalacia, with defective mineralization of newly formed osteoid, is most often caused by aluminium deposition in dialysis patients..$^{25}$

Aluminium overload may interfere with the metabolism of iron and the enzymes involved in heme synthesis, resulting in microcytic anaemia and also some extent resistance to recombinant human erythropoietin. ${ }^{26}$

Aluminium must be monitored routinely in the patients undergoing haemodialysis. Due to all these complications associated with aluminium there is need for concern to check the levels of aluminium in patients undergoing dialysis.

\section{Objective of the Study}

To measure the serum aluminium levels in patients undergoing haemodialysis at KIMS Hospital and Research centre.

\section{MATERIALS AND METHODS}

A Hospital based prospective study was conducted in the Dialysis unit of Nephrology department, Kempegowda Institute of Medical Sciences and Research Centre Hospital (KIMS), Bengaluru. The complete research project was done according to the permission granted by the Human ethical committee of Visveswarapura Institute of Pharmaceutical sciences (V.I.P.S) Bengaluru.

\section{Study Criteria}

\section{Inclusion criteria}

- Outpatients undergoing haemodialysis at dialysis centre of KIMS hospital and research centre.

- Patients on haemodialysis for more than 6 months.

- Patients of both genders.

- Age group $>18$ years.

\section{Exclusion criteria}

- Patients not consenting to take part in the study.

- Patients undergoing peritoneal dialysis.

- Patient data relevant to the study was obtained from the Patients Profile and laboratory reports recorded in the self-designed patient data collection form.

- A data collection form was designed to document the following details:

- Patient demographics- Name, age, sex, body weight.

- Patient/caregiver socio-economic data like address, education, occupation and income.

- Past medical and medication history, any drug allergy, family history of patients.

- Laboratory data.

- Drug data which includes name of the drug, dosage regimen (dose, form, route of administration, frequency) and duration of therapy.

The study was performed on 50 patients who were on maintained Haemodialysis for more than 6 months, which were performed using Fresenius machine 40008s and Baxter- TINA, Polysulfide membrane dialyser was used. Reverse osmosis water was prepared in own plant. All patients were on dialysis twice or three times per week, each session lasting 4-5 hrs depending on the need and condition of the patient. $5 \mathrm{ml}$ of the blood was drawn from the antecubital vein from the patient before haemodialysis process in an aluminium free plastic tube. Only plastic materials were used to prevent contamination.Collected blood samples were estimated by Graphite Furnace Atomic Absorption Spectrometry (GFAAS). During the day of sample collection no patient received blood transfusion and no patients were consuming aluminium containing medications

Frequencies of abnormal aluminium level in the haemodialysis patients were reported. The details about the use of different objects/materials/drugs which were probable source of aluminium were collected from the patients. Further the patients were educated about the role of such materials on their health and were also educated about adherence to diet and medications as prescribed.

The dialysis fluids of 6 batches were tested similarly for the presence of aluminium to correlate the possible contamination of dialysis fluid and the results was compared with European guidelines. The reverse osmosis water was also tested for aluminium content. Patients were educated regarding possible sources of aluminium and methods to avoid it.

\section{RESULTS}

The present study included 50 patients out of which $80 \%$ (40) were male and $20 \%$ (10) were female. Analysis of 
Data indicates that: the patients involved were in the age group between 20-86 years with an average age of 51.4 years. (Figure 1)

The age distribution were: (3)18-29 years 6\%, (5) 30-39 years $10 \%$, (13) $40-49$ years $26 \%$, (14) $50-59$ years $28 \%$, (10) 60-69 years $20 \%$, (3) $70-79$ years $6 \%$, (2) $80-90$ years $4 \%$ respectively. The majority of the patients were in the age group of (14)50-59 years i.e. $28 \%$. (Table 1).

Out of 50 study subjects, 30 of the patients $(60 \%)$ resided in the rural regions while 20 of the patients were from the urban region $(20 \%)$. the education level of the patients was out of 50 patients, $3(6 \%)$ patient had no formal education, whereas $14(28 \%)$ patients were educated up to primary school followed by $23(46 \%)$ patients had completed secondary schooling and then $10(20 \%)$ patients were graduates. (Table 2) (Figure 2).

In the study patients included the common underlying causes of CRF / hemodialysis. Diabetic nephropathy $26(52 \%)$ of the patients, hypertensive nephrosclerosis $14(28 \%)$ of the patients, chronic glomerulonephritis $6(12 \%)$, polycystic kidney disease $3(6 \%)$, reflux nephropathy $1(2 \%)$ and indeterminate causes $1(2 \%)$ (Figure 3).

Serum aluminium levels of 50 patients were; $6(12 \%)$ patients had serum aluminium levels within baseline i.e $20 \mu \mathrm{g} / \mathrm{L}, 18(36 \%)$ patients had serum aluminium levels $21-60 \mu \mathrm{g} / \mathrm{L}$ and $26(52 \%)$ of the patients had serum aluminium levels above $60 \mu \mathrm{g} / \mathrm{L}$. (Table 3) and Aluminium

Table 1: Age Distribution of Patients Studied.

\begin{tabular}{ccc} 
Age (Years) & Number of Patients & Percentage (\%) \\
\hline $18-29$ & 3 & 6.0 \\
$30-39$ & 5 & 10.0 \\
$40-49$ & 13 & 26.0 \\
$50-59$ & 14 & 28.0 \\
$60-69$ & 10 & 20.0 \\
$70-79$ & 3 & 6.0 \\
$80-90$ & 2 & 4.0 \\
Total & 50 & 100 \\
\hline
\end{tabular}

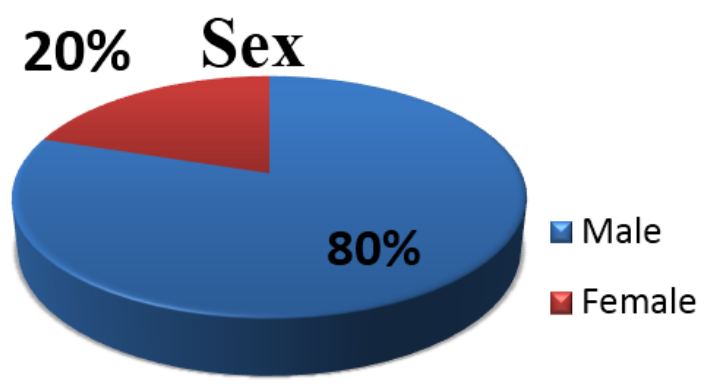

Figure 1: Pie chart showing gender distribution. levels of Dialysis Fluid and Reverse osmosis (RO) water was also measured in the batches aluminium content varied in the dialysate fluid Dialysis Fluid $1(22 \mu \mathrm{g} / \mathrm{L}$ Aluminium Levels) Dialysis Fluid 2 ( $9.6 \mu \mathrm{g} / \mathrm{L}$ Aluminium Levels), Dialysis Fluid 3 (39 $\mu \mathrm{g} / \mathrm{L}$ Aluminium Levels), Dialysis Fluid 4 (26.8 $\mu \mathrm{g} / \mathrm{L}$ Aluminium Levels), Dialysis Fluid $5(41 \mu \mathrm{g} / \mathrm{L}$ Aluminium Levels) and Dialysis Fluid $6(12 \mu \mathrm{g} / \mathrm{L}$ Aluminium Levels) while In reverse osmosis water the aluminium content was in normal limits (Table 4) The association between the dialysis treatment period and the age of serum $\mathrm{Al}$ study patients indicates that (17) 65.3 percent of serum Aluminium patients $>60 \mu \mathrm{g}$ / L have been on haemodialysis for over 4 years. Only $>50$ years of age were 73 per cent of patients with equally high Aluminium serum levels. As the length of haemodialysis raises serum Aluminium levels are also increased proportionately. (Table 5)

\section{DISCUSSION}

Aluminium toxicity is characterized by progressive neurological deterioration leading to death related to status epilepticus. Dalysis dementia is a progressive, neurologic condition identified for chronic renal failure in patients with long-term intermittent haemodialysis. A speech impairment accompanied by dementia, convulsions and myoclonus is the first symptom in these patients. The condition, usually arising after 3-7 years of treatment with dialysis, may be due to aluminium poisoning. In these patients the aluminium content of brain, muscle and bone increases. ${ }^{27}$

To assess aluminium exposure and the risk of aluminium toxicity, serum aluminium levels should be measured at least yearly and every 3 months in those haemodialysis patients who have chances of aluminium toxicity. Baseline levels of serum aluminium should be less than $20 \mathrm{mcg} / \mathrm{L}{ }^{28}$

According to Figure 1, Out of 50 study subjects, 30 of the patients $(60 \%)$ resided in the rural regions while 20 of the patients were from the urban region $(20 \%)$.

Analysis of data indicates that: the patients involved in our study were in the age group between $20-86$ years with an average age of 51.4 years. The age distributions were: (3)18-29 years $6 \%$, (5) 30-39 years $10 \%$, (13) 40-49 years $26 \%$, (14) $50-59$ years $28 \%$, (10) $60-69$ years $20 \%$, (3) $70-79$ years $6 \%$, (2) $80-90$ years $4 \%$ respectively. The majority of the patients were in the age group of 50-59 years i.e. $28 \%$ (14) (Table 1).

Figure 2 depicts that out of 50 patients $3(6 \%)$ patient had no formal education, whereas 14 (28\%) patients were educated up to primary school followed by $23(46 \%)$ 
patients had completed secondary schooling and then $10(20 \%)$ patients were graduates.

In the study, patients included the common underlying causes of CRF / haemodialysis are Diabetic nephropathy $26(52 \%)$ of the patients, hypertensive nephrosclerosis $14(28 \%)$ of the patients, chronic glomerulonephritis $6(12 \%)$, polycystic kidney disease $3(6 \%)$, reflux nephropathy $1(2 \%)$ and indeterminate causes $1(2 \%)$ (Figure 3). The causes of CRF can be correlated to the results in a study done by Gupta V (2002), he found that the etiology of CRF/haemodialysis of the patients under his study were due to Chronic glomerulonephritis14, Diabetic nephropathy 13, Arteriolar nephrosclerosis 11, nephrolithiasis 5, reflux uropathy 4, polycystic kidney disease 2 and rapidly progressing glomerulonephritis $1 .{ }^{29}$

We prospectively examined 50 serum aluminium measurements by graphite furnace atomic absorption spectrophotometry of 50 patients at KIMS hospital. Out of 50 serum aluminium measurements $6(12 \%)$ patients had serum aluminium levels within baseline i.e $20 \mu \mathrm{g} /$ liter,

\begin{tabular}{|cccc|}
\hline Table 2: Aluminium Levels of The Patients. \\
\hline $\begin{array}{c}\text { Aluminium } \\
\text { Levels }(\boldsymbol{\mu g} / \mathbf{L})\end{array}$ & $\begin{array}{c}\text { Number of } \\
\text { Patients }\end{array}$ & $\begin{array}{c}\text { Percentage } \\
(\%)\end{array}$ & Mean \pm SD \\
\hline$<20$ & 6 & 12 & $18 \pm 2$ \\
$20-60$ & 18 & 36 & $32.8 \pm 9.8$ \\
$>60$ & 26 & 52 & $162 \pm 70.8$ \\
\hline
\end{tabular}

Table 3: Aluminium Levels of Dialysis Fluid and Reveres Osmosis (RO) Water.

\begin{tabular}{cc} 
Fluid & Aluminium Levels $(\boldsymbol{\mu g} / \mathbf{L})$ \\
\hline Dialysis Fluid 1 & 22 \\
Dialysis Fluid 2 & 9.6 \\
Dialysis Fluid 3 & 39 \\
Dialysis Fluid 4 & 26.8 \\
Dialysis fluid 5 & 41 \\
Dialysis fluid 6 & 12 \\
R O water & $<10$ \\
R O water & $<10$ \\
\hline
\end{tabular}

Table 4: Comparison Between Duration Since Haemodialysis With Aluminium Levels of The Patients.

\begin{tabular}{cccc}
$\begin{array}{c}\text { Duration Since } \\
\text { Haemodialysis. }\end{array}$ & $\begin{array}{c}\text { Aluminium } \\
\text { Levels }(\boldsymbol{\mu g} / \mathrm{L})\end{array}$ & $\begin{array}{c}\text { Number of } \\
\text { Patients }\end{array}$ & $\begin{array}{c}\text { Percentage } \\
(\%)\end{array}$ \\
\hline UPTO 1 YEAR & $25.27 \pm 6.48$ & 18 & 36 \\
$>1$ - 3 YEARS & $58.66 \pm 18.60$ & 10 & 20 \\
$>3-5$ YEARS & $147.5 \pm 22.71$ & 14 & 28 \\
$>5$ - 7 YEARS & $180.6 \pm 85.5$ & 5 & 10 \\
$>7$ YEARS & $302.6 \pm 43.07$ & 3 & 6 \\
\hline
\end{tabular}

$18(36 \%)$ patients had serum aluminium levels $21-60 \mu \mathrm{g} /$ liter and $26(52 \%)$ of the patients had serum aluminium levels above $60 \mu \mathrm{g} /$ liter (Table 3 ). Serum aluminium level ranged from 14.5-350.4 $\mu \mathrm{g} /$ liter and average being 99.6 $\mathrm{g}$ /liter. According to KDOQI, National Kidney Foundation, Serum aluminium baseline levels should be $<20$ microgram /liter. As serum aluminium levels are between 20-60 micrograms/liter, a search for and elimination of all sources of aluminium should be performed. Hence 26 (52\%) of the patient had serum aluminium levels above the normal range. According to Jaffe JA et al. Study, they conducted a retrospective study at Da vita Franklin Dialysis center located in Philadelphia. They measured serum aluminium levels on blood samples by using graphite furnace atomic absorption spectrophotometry method. The method for analyzing blood and dialysate fluid was same and did not change during the course of the study. Aluminium levels were dramatically elevated in patients with acute aluminium

Table 5: Comparison Between Duration Since Heamodialysis With Aluminium Levels of The Patients.

\begin{tabular}{cccc}
$\begin{array}{c}\text { Duration Since } \\
\text { Haemodialysis. }\end{array}$ & $\begin{array}{c}\text { Aluminium } \\
\text { Levels }(\boldsymbol{\mu g} / \mathrm{L})\end{array}$ & $\begin{array}{c}\text { Number of } \\
\text { Patients }\end{array}$ & $\begin{array}{c}\text { Percentage } \\
(\%)\end{array}$ \\
\hline UPTO 1 YEAR & $25.27 \pm 6.48$ & 18 & 36 \\
$>1$ - 3 YEARS & $58.66 \pm 18.60$ & 10 & 20 \\
$>3-5$ YEARS & $147.5 \pm 22.71$ & 14 & 28 \\
$>5$ - 7 YEARS & $180.6 \pm 85.5$ & 5 & 10 \\
$>7$ YEARS & $302.6 \pm 43.07$ & 3 & 6 \\
\hline
\end{tabular}

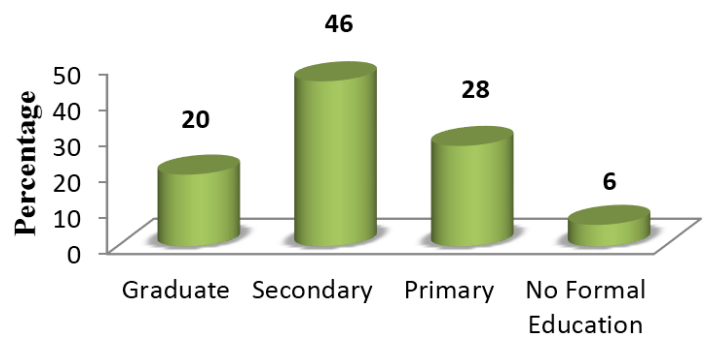

Education Level of the Patient

Figure 2: Bar chart showing educational level of the patients.

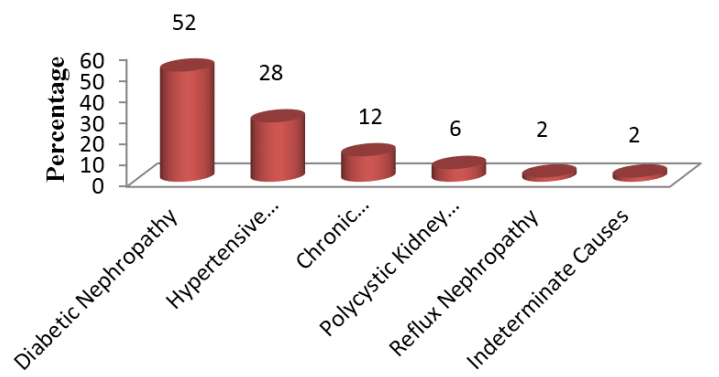

Reason for CRF

Figure 3: Bar graph representing diagnosis conditions which lead for CRF.

Indian Journal of Pharmacy Practice, Vol 13, Issue 3, Jul-Sep, 2020 
toxicity i.e $400-1000 \mu \mathrm{g} /$ liter, as well as those suffering from aluminium encephalopathy. ${ }^{30}$

The aluminium content in the batches of dialysis fluid and reverse osmosis water is shown in Table 4 accordingly. In the dialysate fluid, the aluminium content varied, reaching above the defined safety limits i.e.10 $\mu \mathrm{g} /$ liter. In reverse osmosis water the aluminium content was in normal limits. Dialysis fluid aluminium measurement values of

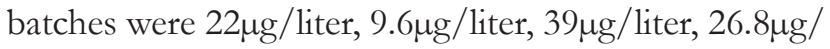
liter, $41 \mu \mathrm{g} /$ liter and $12 \mu \mathrm{g} /$ liter. While, reverse osmosis water sample aluminium level was $<10 \mu \mathrm{g} / \mathrm{liter}$. (Table 4) According to European Best Practice Guidelines for haemodialysis maximum aluminium concentration in dialysis fluid and reverse osmosis water should not exceed from $10 \mu \mathrm{g} / \mathrm{L}$. Our analysis of the aluminium content in the dialyaste fluid showed that the water source could have contributed to the high serum aluminium levels in these patients as five out of six dialysate fluid batches showed aluminium content above the permissible limits. In a study conducted by Nampoory MRN et al. in Kuwait, a similar result was found, analyzing 25 batches of dialysate fluid and reverse osmosis water. In the dialysate fluid, the aluminium content was higher than the permissible safety limit. ${ }^{31}$

A comparison between duration since haemodialysis and aluminium levels of the patients was done in Table 5. It illustrates that as the duration (in years) of haemodialysis is increased, the level of Aluminium is also increased in the patients.

The dialysis unit in KIMS hospital (place of study) has been operational since 5 years. In case of patients who were undergoing haemodialysis for $>5$ years and/or undergoing haemodialysis in other dialysis centre before shifted over to the dialysis centre at KIMS hospital, the detailed history regarding their medications and dialysis procedure were incompletely or not available at all. Hence there may be a possibility of use of aluminium containing medications especially as phosphate binders to overcome hyperphosphatemia condition in Dialysis patients. Also whether the dialysate fluid/RO water was monitored for aluminium levels in other haemodialysis center is not known. All such factors may be the source contributing to high levels of aluminium measured in the present study in the patient at dialysis centre at KIMS hospital, Bengaluru. As aluminium cannot be eliminated from the body in CRF patients, hence it gets accumulated and can cause aluminium toxicity in the dialysis patients.

Most of the patients were from rural area $(60 \%)$ where even today people use aluminium vessels to cook and to preserve cooked food, which could be one of the sources of aluminium for CRF patients.
Renal insufficiency patients often find themselves on several drugs. About 80-90 per cent of people with chronic renal disease receive many other medications for eg: antihypertensive, erythropoietin, iron supplements, medications for treating electrolyte imbalance, diuretics, drugs for heart failure etc. Drugs or medications given to the CRF patients could act as a hidden aluminium source. While complying with the quality-related pharmacopoeias standard, drugs may still have aluminium as impurity and may therefore be an additional source of aluminium for CRF patients.

Also in our study patients out of 50 patients, 10 of the patients are agriculturist, 2 of the patients are driver and 1 patient is a mason (Building worker), these patients have chance of occupational exposure to aluminium. Hence, the patients were educated regarding possible sources of aluminium and to avoid it. Also by the help of dietician, the patients were given diet chart and recommendations were given by using a pamphlet to avoid or prevent further aluminium intoxication. Education and counselling regarding the importance of therapy for anaemia, osteodystrophy should be provided to the patients and/or care givers. Annual monitoring of serum aluminium measurements is recommended for patients with dialysis susceptible to toxic accumulation from contaminated dialysis fluid or aluminium-containing medicines. ${ }^{32}$

\section{CONCLUSION}

Our research reveals that aluminium toxicity remains a problem in haemodialysis patients. Patients over 50 years of age and over 3 years of dialysis need to be carefully monitored for aluminium toxicity. In our patients, dialysate appears to be the main source of elevated serum aluminium, the use of aluminium utensils and food habits.

Awareness has to be brought among the nephrologists and the public regarding the issue of aluminium toxicity in CRF patients across the country as the aluminium levels are not measured commonly in dialysis patient and also there is no much data available regarding this. Drugs, different dosage forms, intravenous preparations, Total parental nutrition is to be manufactured especially for CRF patients with aluminium free materials. Also limits for aluminium must be set up of pharmacopoeial grade by drug authorities.

The reason to highlight the issue of aluminium toxicity is that it exhibits how in developing countries, despite sound scientific research revealing a clear and significant healthcare problem, we don't have a lot of data about this. This highlights our responsibility as a clinical pharmacist as part of the healthcare team not only to define a 
problem, but also to ensure that healthcare professionals, pharmaceutical industries and government sectors will be properly addressing the issue. In the perspective of ongoing therapeutic management of dialysis patients, the present data can be judiciously implemented by the clinicians.

\section{ACKNOWLEDGEMENT}

We are thankful for the whole team of Nephrology Department of KIMS Hospital and Research centre for supporting this study and we also thank Surya Analyticals and Research Centre, Bengaluru and Dr. Lal Path labs, Bengaluru for providing us the accurate results.

\section{CONFLICT OF INTEREST}

The authors declare no conflicts of interest.

\section{ABBREVIATIONS}

CRF: Chronic Renal Failure; FAAS: Flame Atomic Absorption Spectrometry; GFAAS: Graphite Furnace Atomic Absorption Spectrophotometry; GI: Gastro Intestinal; IV: Intravenous; KIMS: Kempegowda institute of Medical Sciences; KDOQI: Kidney Disease Outcomes Quality Initiative; RO: Reverse Osmosis; ROS: Reactive Oxygen Species; TPN: Total Parentral Nutrition; VIPS: Visveswarapura Institute of Pharmaceutical Sciences.

\section{REFERENCES}

1. Hellstrom $\mathrm{HO}$, Mallmin $\mathrm{H}$, Michaelsson $\mathrm{K}$. The aluminium content of bone increases with age but is not higher in hip fracture cases with and without dementia compared to controls. Osteoporos Int. 2005; 16(12):1982-8. DOI:10.1007/s00198-005-1981-6

2. Berlyne GM, Ben-Ari J, Pest D, Weinberger J, Stern M, Levine R, et al. Hyperaluminaemia from aluminium resins in renal failure. Lancet. 1970; 2(7671):494-6. DOI:10.1016/s0140-6736(70)90113-3

3. Berlyne GM, Ben-Ari J, Knopf E, Yagil R, Weinberger G, Danovitch GM. Aluminium toxicity in rats. Lancet. 1972; 1(7750):564-8. DOI:10.1016/s01406736(72)90357-1

4. Sherrard DJ. Letter: The myth of aluminium toxicity. N Engl J Med. 1974;290(13):750. DOI:10.1056/NEJM197403282901328

5. Alfrey AC, LeGendre GR, Kaehny WD. The dialysis encephalopathy syndrome. Possible aluminium intoxication. N Engl J Med. 1976;294(4):184-8. DOI:10.1056/NEJM197601222940402

6. Alfrey AC. Aluminium metabolism and toxicity in uremia. J UOEH. 1987;9 (Suppl):123-32.

7. Carl AB, Edward RA. Fundamentals of clinical chemistry. 5th ed. Saunders: Harcourt India. 2008.652-3.

8. Meira RD, Carbonara CEM, Quadros KRDS, Santos CUD, Schincariol P, Pêssoa GS, etal.The enigma of aluminium deposition in bone tissue froma patient with chronic kidney disease: A case report. J Bras Nefrol. 2018; 40(2):201-5. doi:10.1590/2175-8239-JBN-3882.Epub2018Jun 4. DOI:10.1590/2175-8239JBN-3882

9. Bernardo JF, Edwards MR, Barnett B. Toxicity, aluminium. 2017. [cited 2018 June 28th] Available from: http://emedicine.medscape.com/article/165315overview.

10. Kawahara M, Kato-Negishi M. Link between Aluminium and the Pathogenesis of Alzheimer's Disease: The Integration of the Aluminium and Amyloid
Cascade Hypotheses. Int J Alzheimers Dis. 2011; 2011:276393. doi: $10.4061 / 2011 / 276393$.

11. Lukiw WJ, Pogue Al. Induction of specific micro RNA (miRNA) species by ROS-generating metal sulfates in primary human brain cells. J Inorg Biochem. 2007;101(9):1265-9. Epub 2007 Jun 13. DOI: 10.1016/j.jinorgbio.2007.06.004

12. Wu Z, Du Y, Xue H, Wu Y, Zhou B. Aluminium induces neurode generation and its toxicity arises from increased iron accumulation and reactive oxygen species (ROS) production. Neurobiol Aging. 2012; 33(1):199.e1-12. doi: 10.1016/j.neurobiolaging.2010.06.018. Epub 2010 Jul 31. DOI: 10.1016/j. neurobiolaging.2010.06.018

13. Fulgenzi A, Vietti D, Ferrero ME. Aluminium involvement in neurotoxicity. Biomed Res Int. 2014; 2014:758323. doi: 10.1155/2014/758323. Epub 2014 Aug 27. DOI: 10.1155/2014/758323

14. Peterson JR, Mohammad AA. Clinical and forensic applications of capillary electrophoresis. Totowa, New Jersey. Humana press. 2001; 388-9.

15. KDOQI, National Kidney Foundation. K/DOQI clinical practice guidelines for bone metabolism and disease in children with chronic kidney disease. Am J Kidney Dis 2005; 46(4 Suppl 1):S1-1021.

16. Priest ND. The biological behaviour and bioavailability of aluminium in man, with special reference to studies employing aluminium-26 as a tracer: Review and study update. J Environ Monit. 2004; 6(5):375-403. Epub 2004 Apr 23. DOI: $10.1039 / b 314329 p$

17. Bohrer D, Denise C, Sandra MRO, Paulo CN, Leandro MC, Solange GP. Drugs as a hidden source of aluminium for chronic renal patients. Nephrol Dial Transplant. 2007; 22(2):605-11. Epub 2006 Oct 11. DOI: 10.1093/ndt/gfl569

18. Klotz K, Weistenhöfer W, Neff F, Hartwig A, Thriel VC, Drexler H. The Health Effects of Aluminium Exposure. Dtsch Arztebl Int. 2017;114(39):653-9. DOI: 10.3238/arztebl.2017.0653.

19. Blaylock RL. The danger of excessive vaccination during brain development: The case for a link to Autism Spectrum Disorders (ASD).2008.[Cited 2020 MAR 16]: Available from https://www.healmindbody.com/the-danger-of-excessivevaccination-during-brain-development-the-case-for-a-link-to-autism-spectrumdisorders/

20. Fortenberry M, Hernandez L, Morton J. Evaluating Differences in Aluminium Exposure through Parenteral Nutrition in Neonatal Morbidities. Nutrients. 2017; 9(11):1249. doi:10.3390/nu9111249

21. Toxicological profile for aluminium, US department of health and human services, Public Health Service, Agency for Toxic Substances and Disease Registry. 2008. [Cited 2020 April 4th]. Available from: URL https://www.atsdr. cdc.gov/toxprofiles/tp22.pdf

22. Luis GMA, Garcia FD, Silva VS, Baretti P, Balbi AL, Caramoni JT, et al. Dialysis encephalopathy secondary to aluminium toxicity diagonised by bone biopsy. Nephrology, Dialysis, Transplantation: Official Publication of the European Dialysis and Transplant Association: European Renal Association. 2005; 20(11):2581-2. 10.1093/ndt/gfi072.

23. Walton JR. Aluminium Disruption of Calcium Homeostasis and Signal Transduction Resembles Change that Occurs in Aging and Alzheimer's disease. J Alzheimers Dis. 2012; 29(2):255-73. doi: 10.3233/JAD-2011-111712.

24. Tsai, M., Fang, Y., Liou, H. et al. Association of Serum Aluminium Levels with Mortality in Patients on Chronic Hemodialysis. Sci Rep 8, 16729 (2018). https:// doi.org/10.1038/s41598-018-34799-5

25. El-Kishawi AM, El-Nahas AM. Renal Osteodystrophy: Review of the Disease and its Treatment. Saudi J Kidney Dis Transpl. 2006; 17:373-82. [cited 2020 Apr 5]; Available from: http://www.sjkdt.org/text.asp?2006/17/3/373/35770

26. Singh AK, Fishbane S. The optimal hemoglobin in dialysis patients: a critical review. Semin Dial. 2008; 21(1):1-6

27. Klaassen. Casarett and doull's toxicology the basic science of poisons. 8th ed. Mcgraw-hill medical publishing division. Toxic Agent. 2012.960-1.

28. National Kidney Foundation: K/DOQI Clinical Practice Guidelines for Bone Metabolism and Disease in Chronic Kidney Disease. Am J Kidney Dis. 2003;42(Suppl 3):S1-S202.

29. Gupta V. Renal osteodystrophy and aluminium bone disease in patients with chronic renal failure. JK-Practitioner. 2003; 10(2):107-11.

30. Jaffe JA, Liftman C, Glickman JD. Frequency of elevated serum aluminium levels in adult dialysis patients. Am J Kidney Dis. 2005;46(2):316-9.

31. Nampoory MR, Al-Hilali N, Seshadri MS, Abdulla A, Kanagasabhapathy AS, Nayak NC, et al. Aluminium monitoring for chronic renal failure patients in kuwait. Saudi J Kidney Dis Transpl. 1996; 7(1):27-30.

32. Ron B. Schifman MD, Daniel R, Luevano BS. Aluminium Toxicity. Arch Pathol Lab Med. 2018; 142. 